\title{
Case Report Extradigital Glomus Tumor of Thigh
}

\author{
Kemal Beksaç, ${ }^{1}$ Lutfi Dogan, ${ }^{1}$ Nazan Bozdogan, ${ }^{2}$ Gulay Dilek, \\ Gokhan Giray Akgul, ${ }^{1}$ and Cihangir Ozaslan ${ }^{1}$ \\ ${ }^{1}$ General Surgery Department, Dr. Abdurrahman Yurtaslan Ankara Oncology Hospital, 06200 Ankara, Turkey \\ ${ }^{2}$ Pathology Department, Dr. Abdurrahman Yurtaslan Ankara Oncology Hospital, 06200 Ankara, Turkey \\ Correspondence should be addressed to Kemal Beksaç; kemalbeksac@yahoo.com
}

Received 13 May 2015; Accepted 22 June 2015

Academic Editor: Francesco Petrella

Copyright (C) 2015 Kemal Beksaç et al. This is an open access article distributed under the Creative Commons Attribution License, which permits unrestricted use, distribution, and reproduction in any medium, provided the original work is properly cited.

\begin{abstract}
Glomus tumors are benign neoplasms that arise from neuromyoarterial glomus bodies. They represent around 1-5\% of all softtissue tumors. High temperature, sensitivity, and pain and localized tenderness are the classical triad of symptoms. Most glomus tumors represent in the subungual area of digits. Extradigital glomus tumors are a very rare entity. There are rare cases of these tumors reported to be in shoulder, elbow, knee, wrist, even stomach, colon, and larynx. We are reporting a case of a glomus tumor on thigh and discuss the histological and immunohistochemical features.
\end{abstract}

\section{Introduction}

Glomus tumors are benign neoplasms that arise from neuromyoarterial glomus bodies [1]. Glomus tumors represent around $1-5 \%$ of all soft-tissue tumors and $1-5 \%$ of all hand tumors [2]. They present with a classical triad of symptoms of high temperature, sensitivity, and pain and localized tenderness [3]. Most glomus tumors represent in the subungual area of digits and extradigital tumors are a rare entity. There are rare cases of these tumors reported to be in shoulder [1], elbow [4], knee [5], wrist [6], even stomach [7], colon [8], and larynx [9]. Histologically, the tumors have variable quantities of glomus cells, blood vessels, and smooth muscle cells. They are classified as solid glomus tumors, glomangiomas, and glomangiomyomas. Malignant transformation is rare. Folpe et al. propose the classification of malignant tumor as tumors with a deep location and a size of more than $2 \mathrm{~cm}$ or atypical mitotic figures or moderate-to-high nuclear grade and $\geq 5$ mitotic figures/50 HPF [10]. We are reporting a case of a glomus tumor on thigh and discuss the histological and immunohistochemical features.

\section{Case}

A 39-year-old male patient was referred to our clinic with a painful mass on his left thigh. Lesion was located on the posterolateral side and about $1 / 3$ proximal to the head of femur. The pain had begun 2 years ago and the mass gradually increased in size during this period. The pain was moderate with a visual analogue score (VAS) 6 out of 10. Further examination with Computerized Tomography (CT) revealed a $15 \times 10 \mathrm{~mm}$ mass in subcutaneous fat tissue. Fine needle biopsy was performed and the aspirate exhibited groups of cohesive, uniform, small, round-to-polygonal cells with scanty cytoplasm, indistinct cell borders, and round nucleus with homogeneous chromatin (Figure 1). Cells were stained with TLE-1 and this was suspicious of synovial sarcoma. Therefore lesion is excised with clear surgical margins.

Grossly lesion had a size of $1 \times 1 \times 1.2 \mathrm{~cm}$. It was a well circumscribed blue-red nodule and had a soft consistency. In histopathologic examination, tumor was well circumscribed and encapsulated in most areas. Tumor showed diffuse or nested growth pattern. Tumor consisted of round and oval monotonous cells with pale cytoplasm and punched-out rounded nucleus. Tumor cells had no mitosis.

In immunohistochemical examination tumoral cells stained smooth muscle actin and TLE-1. Pan cytokeratin, CD31, CD34, S-100 Fli-1, and D240 were not stained. Thus it was consistent with glomus tumor (Figures 2 and 3). No complications were observed in the postoperative period and patient was pain-free after the surgery. 


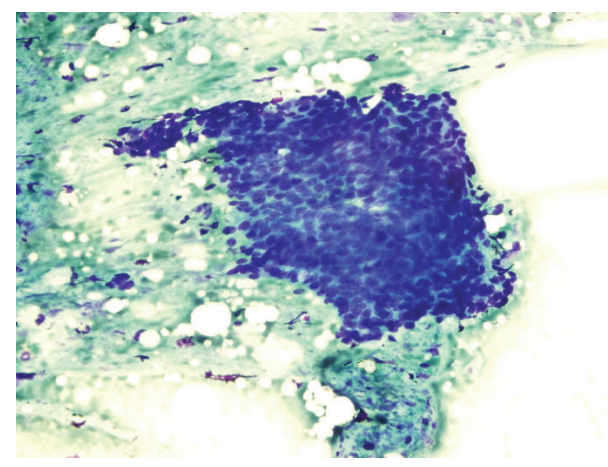

FIGURE 1: Microscopic findings of fine needle biopsy.

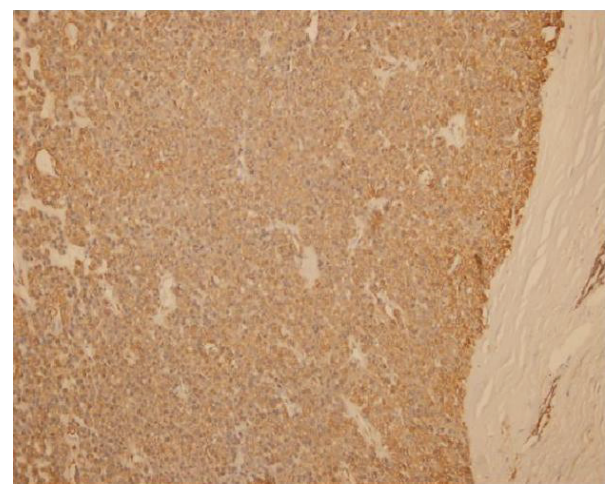

FIGURE 2: Tumoral cells staining with SMA.

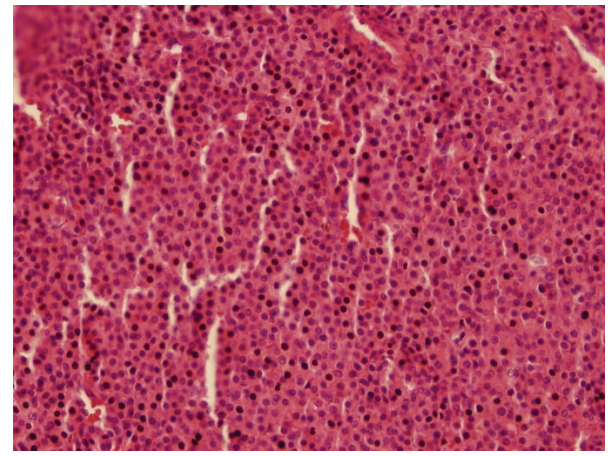

FIgURE 3: Tumor is highlighted with H\&E.

\section{Discussion}

Glomus tumor is a vascular tumor believed to be originating from the cutaneous neuromyoarterial glomus body. Arteriovenous anastomoses are located between a preterminal arteriole and end efferent vein. Although most of cases originate from subungual bed of hand, there are rare cases of extradigital presentation [1,4-9]. These tumors usually present as painful, firm, purplish, solitary subcutaneous nodules. Tumor size is generally small and rarely bigger than $1 \mathrm{~cm}$. Tumors in lower extremity can have a size more than $2 \mathrm{~cm}$ [11]. Magnetic Resonance Imaging (MRI) is an accepted method of evaluation for subungual glomus tumors [12]. In spite of this, there are reports that even MRI is not enough to distinguish all cases [13]. Computerized Tomography (CT) is also an accepted form radiologic evaluation and especially important in the evaluation of gastric glomus tumors. It is not always possible to diagnose extremity glomus tumours with fine needle biopsy.

Treatment of choice for glomus tumor is complete surgical excision. There are also reports of alternative treatment such as sclerotherapy with sodium tetradecyl sulfate, polidocanol, and hypertonic saline and ablative therapy with argon and carbon dioxide and ethanol $[14,15]$.

We reported the case of an extradigital glomus tumor arising in the subcutaneous tissue of thigh. Even though glomus tumors are rare incidents and even rarer to see in extradigital locations, a review of literature suggests that these lesions may be more common than they are thought to be.

\section{Conflict of Interests}

The authors declare that there is no conflict of interests regarding the publication of this paper.

\section{References}

[1] A. Proietti, G. Alì, F. Quilici, P. Bertoglio, A. Mussi, and G. Fontanini, "Glomus tumor of the shoulder: a case report and review of the literature," Oncology Letters, vol. 6, no. 4, pp. 10211024, 2013.

[2] R. C. Akgün, Ü. Ö. Güler, and U. Onay, "A glomus tumor anterior to the patellar tendon: a case report," Acta Orthopaedica et Traumatologica Turcica, vol. 44, no. 3, pp. 250-253, 2010.

[3] M. Sandoval, J. Carrasco-Zuber, and S. Gonzalez, "Extradigital symplastic glomus tumor of the hand: report of 2 cases and literature review," The American Journal of Dermatopathology, vol. 37, no. 7, pp. 560-562, 2015.

[4] J. S. Chun, R. Hong, and J. A. Kim, "Extradigital glomus tumor: a case report," Molecular and Clinical Oncology, vol. 2, pp. 237239, 2013.

[5] R. Gonçalves, A. Lopes, C. Júlio, C. Durão, and R. A. de Mello, "Knee glomangioma: a rare location for a glomus tumor," Rare Tumors, vol. 6, no. 4, article 5588, 2014.

[6] A. K. Balaram, A. R. Hsu, T. B. Rapp, V. Mehta, and R. R. Bindra, "Large solitary glomus tumor of the wrist involving the radial artery," The American Journal of Orthopedics, vol. 43, no. 12, pp. 567-570, 2014.

[7] K.-B. Chen and L. Chen, "Glomus tumor in the stomach: a case report and review of the literature," Oncology Letters, vol. 7, no. 6, pp. 1790-1792, 2014.

[8] R. Barua, "Glomus tumor of the colon. First reported case," Diseases of the Colon and Rectum, vol. 31, no. 2, pp. 138-140, 1988.

[9] N. Aslam, Z.-U.-S. Qazi, A. H. Ahmad, and R. U. Khan, "Malignant glomus tumour of larynx: first case report and literature review," The Journal of Laryngology and Otology, vol. 126, no. 7, pp. 743-746, 2012.

[10] A. L. Folpe, J. C. Fanburg-Smith, M. Miettinen, and S. W. Weiss, "Atypical and malignant glomus tumors: analysis of 52 cases, with a proposal for the reclassification of glomus tumors," The American Journal of Surgical Pathology, vol. 25, no. 1, pp. 1-12, 2001. 
[11] B. Frumuseanu, R. Balanescu, A. Ulici et al., "A new case of lower extremity glomus tumor up-to date review and case report," Journal of Medicine and Life, vol. 5, no. 2, pp. 211-214, 2012.

[12] J.-L. Drape, I. Idy-Peretti, S. Goettmann et al., "Subungual glomus tumors: evaluation with MR imaging," Radiology, vol. 195, no. 2, pp. 507-515, 1995.

[13] S. K. Trehan, E. A. Athanasian, E. F. DiCarlo, D. N. Mintz, and A. Daluiski, "Characteristics of glomus tumors in the hand not diagnosed on magnetic resonance imaging," The Journal of Hand Surgery, vol. 40, no. 3, pp. 542-545, 2015.

[14] A. G. Rao, D. Indira, and J. Kamal, "Extra digital glomangioma," Indian Journal of Dermatology, vol. 55, no. 4, pp. 397-398, 2010.

[15] P. Sanders, R. J. Spouge, M. Akbari, and D. J. Spouge, "Ethanol ablation of extradigital solid glomus tumors," Skeletal Radiology, vol. 43, no. 12, pp. 1755-1759, 2014. 


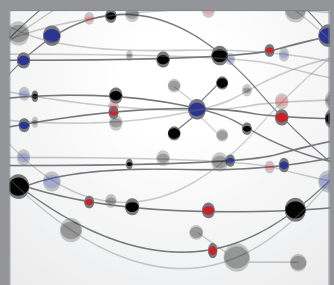

The Scientific World Journal
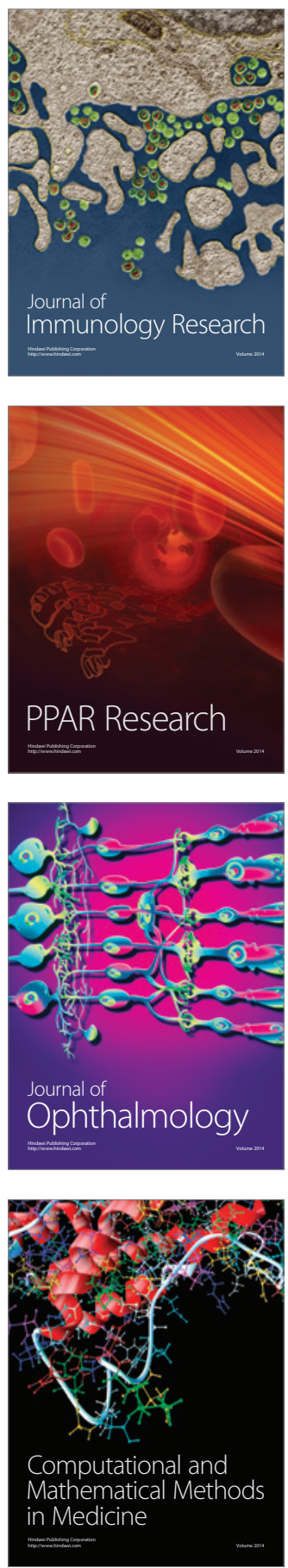

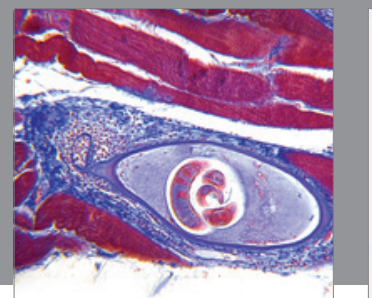

Gastroenterology

Research and Practice
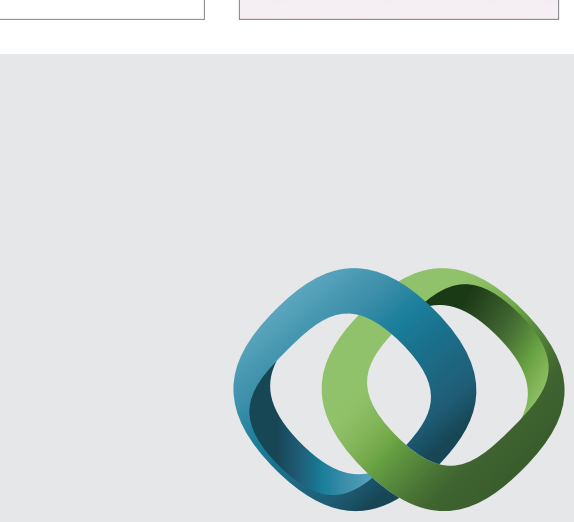

\section{Hindawi}

Submit your manuscripts at

http://www.hindawi.com
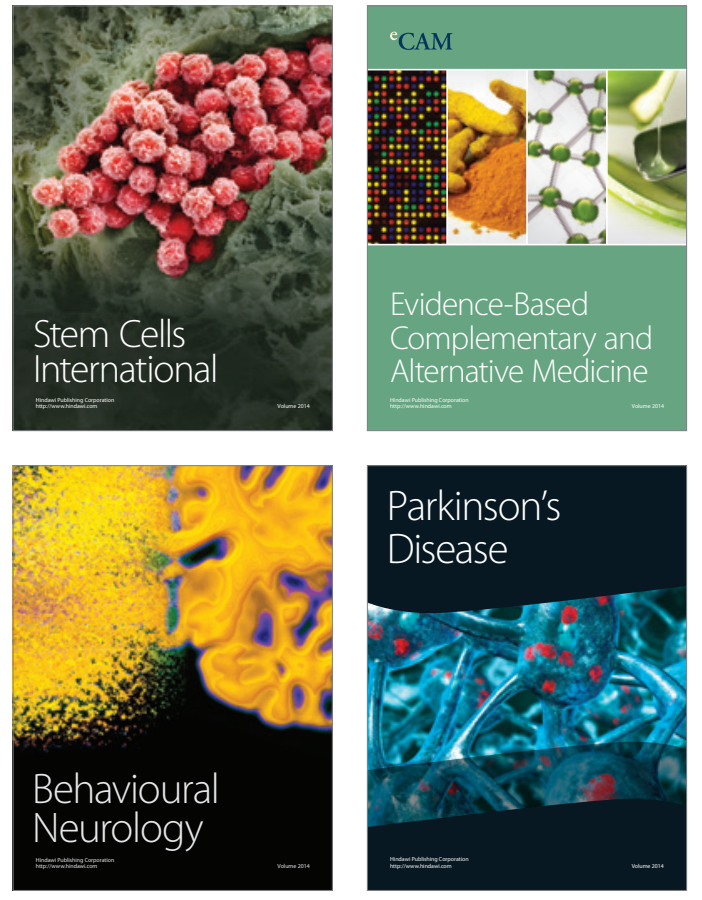
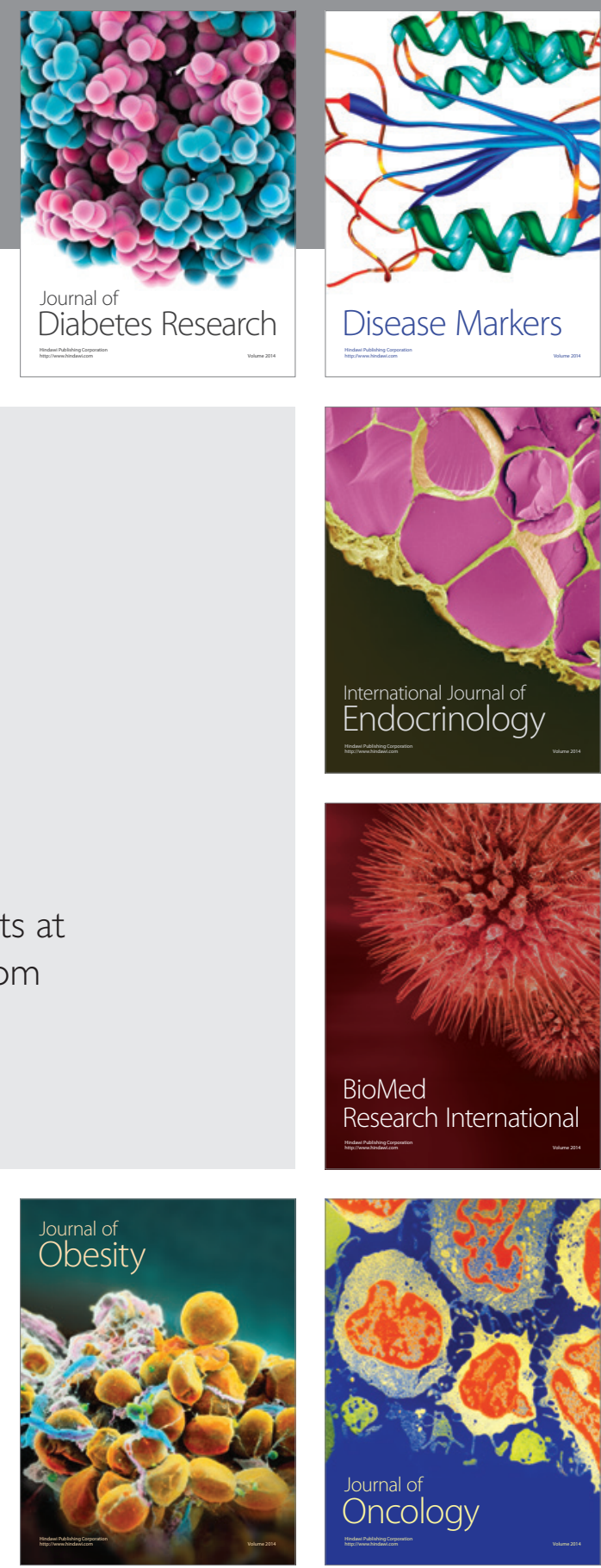

Disease Markers
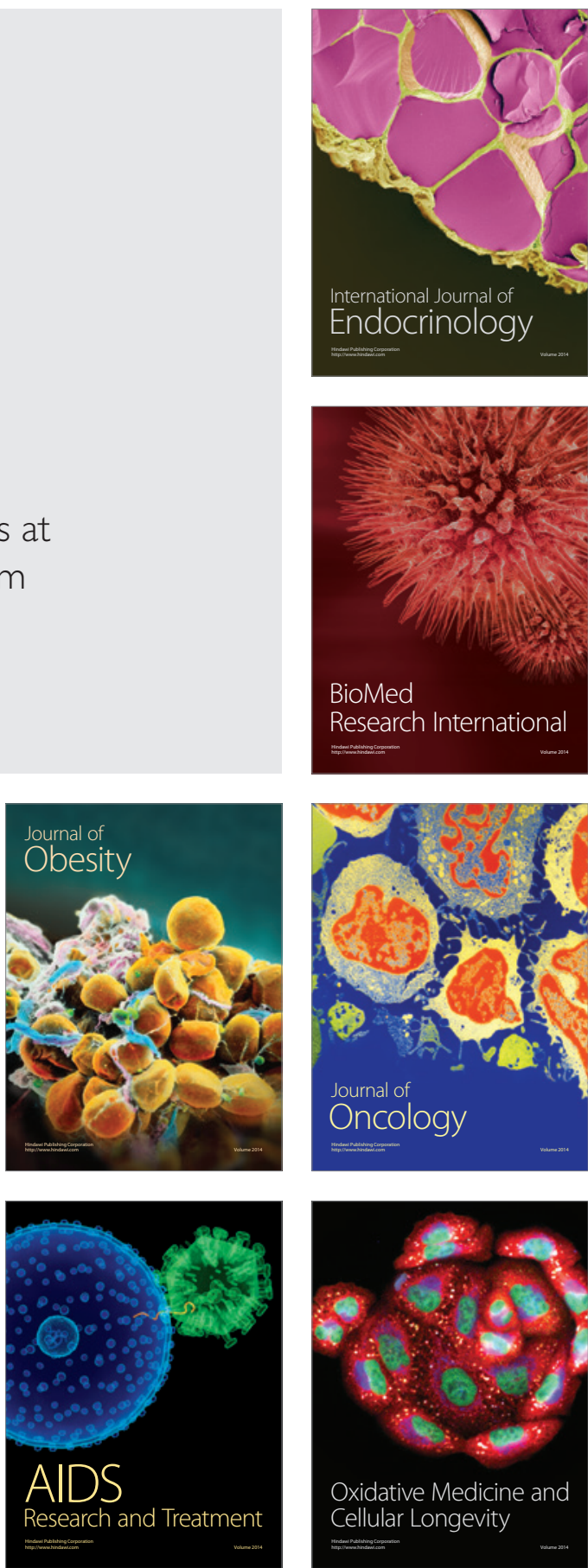